\title{
Isolation and identification of Avibacterium paragallinarum, the causal agent of infectious coryza (IC) from layer chickens in Bangladesh
}

\author{
S. Akter, M. Ali, P. M. Das and M. M. Hossain* \\ Department of Pathology, Bangladesh Agricultural University, Mymensingh-2202, Bangladesh \\ *E-mail: mmhossain04@yahoo.com.au
}

\begin{abstract}
This study was carried out for the isolation and identification of Avibacterium paragallinarum, the etiological agent of infectious coryza (IC). Pathological changes were also investigated that occurred in organs in layer chickens obtained from some selected areas of Bangladesh. A nasal swabs $(n=30)$ from dead chickens and four swabs from live chickens were collected aseptically. The organisms from swabs were cultured in different media, stained, and followed by sugar fermentation and biochemical tests for identification of causal agent. Histopathology of the affected tissues was also carried out. Swabs from nasal passage $(n=30)$ of dead birds died of other diseases cultured but no A. paragallinarum was isolated and identified. Two out of four suspected clinical cases of IC was confirmed by isolation of $A$. paragallinarum. The clinical signs of all four cases were nasal discharge; conjunctivitis with swelling of the sinuses, face and wattles; decreased feed and water intake with reduced egg production. At necropsy, hemorrhages were in mucous membrane of nasal passage and trachea. Histopathology of the nasal septum showed acanthosis, congestion, mucous glandular cell hyperplasia, hyperplasia of nasal sinus and parakeratosis. Further studies involving serological and molecular identification of the etiological agent of IC are warranted.
\end{abstract}

Keywords: Infectious coryza, Avibacterium paragallinarum, Isolation, Identification, Histopathology

\section{Introduction}

Avibacterium paragallinarum (previously called Haemophilus paragallinarum) causes an acute respiratory disease in chickens known as IC, a disease first recognized as a distinct entity in the late 1920's (De Blieck, 1932) and described as roup, cold, contagious or infectious catarrh and uncomplicated coryza (Yamamoto, 1991). Chicken (Gallus gallus) is the natural host for A. paragallinarum and birds of all ages are susceptible. The disease is usually transmitted through drinking water contaminated with infective nasal exudates (Page, 1962). Infection may also occur by contact and by air-borne infected dust and/or droplets.

IC is regarded as a disease limited to the upper respiratory tract (Reid and Blackall, 1984) and infection in the lower respiratory tract (Alder and Page, 1962) may be due to synergism between A. paragallinarum and other respiratory tract pathogens (Reid and Blackall, 1984) like fowl cholera, pox, chronic respiratory disease (CRD), and Pseudomonas aeruginosa infection (Giurov, 1984). Due to the phenomenon that the disease proved to be infectious only in the nasal passages the name "Infectious Coryza" was adopted (Beach and Schalm, 1936).

The clinical signs associated with this disease include a nasal discharge, conjunctivitis with swelling of the sinuses, face and wattles, diarrhoea, decreased feed and water consumption, retarded growth in younger chickens, increased number of culls and reduced egg production (10-40\%) (Eaves et al., 1989; Calnek et al., 1991). Lesions associated with the disease reflect an acute catarrhal inflammation of the upper respiratory tract.

A. paragallinarum is a Gram negative, polar staining, non-motile bacterium. In 24-48 hrs cultures, it appears as short rods or coccobacilli $1-3 \mu \mathrm{m}$ in length and $0.4-0.8 \mu \mathrm{m}$ in width, with a tendency for filament formulation. The organism undergoes degeneration within 48-60 hrs, showing fragments and indefinite forms (Yamamoto, 1991).

In Bangladesh, the information on IC is very scanty (Talha et al., 2001). IC had been diagnosed on the basis of postmortem examination of dead birds but no attempt was undertaken to isolate the causal agent of IC, A. paragallinarum. Therefore, this investigation was undertaken with a view (a) to isolate and identify the etiological agent of IC, A. paragallinarum from layer chickens and (b) to determine the pathological lesions in affected organs. 


\section{Materials and Methods}

The present study was divided in three phases. First phase included, isolation and identification of Staphylococcus aureus, that supplied nicotinamide adenine dinucleotide (NAD) and acted as feeder colony for Aviobacterium paragallinarum, the second phase included isolation and identification of Avibacterium paragallinarum and the third phase included pathological study of affected organs. The study was conducted during June 2011 to May 2012.

\section{Isolation of Staphylococcus aureus and Avibacterium paragallinarum}

For the isolation of Staphylococcus aureus, 10 nasal swab samples from nasal passages of 10 live layer chickens were collected aseptically from Bangladesh Agricultural University (BAU) poultry farm. For the isolation and identification of Avibacterium paragallinarum, 30 nasal swab samples and their heads from 30 dead birds died of due to different diseases were collected from SK Veterinary Diagnostic Center, Mymensingh and four clinical samples: two from Gazipur and two from Tangail, respectively. The field nasal swab samples were aseptically collected into nutrient broth (NB) and carried to the laboratory for the isolation and identification of the etiological agents.

\section{Bacteriological media for culture}

Both solid and liquid media included Blood agar (Techno Pharma., India), Nutrient agar (Techno Pharma., India), Mannitol salt agar (Techno Pharma., India) and Nutrient broth (HiMedia Lab. Pvt., India) were used.

\section{Sugars and reagents for biochemical tests}

Dextrose (LOBA Chemic Pvt. Ltd., India), Sucrose (Wako, Japan), Lactose (Merc, England), Maltose (Techno Pharma., India), Mannitol (Beximco Pharma., Germany), Galactose (LOBA Chemic Pvt. Ltd., India), Methyl Red and Voges-Proskauer broth (MR-VP broth) (Difco, USA), Peptone water and Phosphate buffer solution were used.

\section{Primary culture of Staphylococcus aureus}

Primary growth of all kinds of bacteria was carried out in nutrient broth. Ten nasal swab samples from live birds were collected in sterile cotton bud by gentle touch, and then inoculated into the nutrient broth, incubated over night at $37^{\circ} \mathrm{C}$ to obtain the primary culture of Staphylococcus aureus (Brooks et al., 2002; Freeman, 1985; Merchant and Packer, 1967).

\section{Primary culture of $A$. paragallinarum}

For isolation and identification of $A$. paragallinarum, S. aureus was needed. Accordingly, S. aureus from 10 live birds were isolated and identified. This previously isolated $S$. aureus cultured on blood agar media to produce NAD for $A$. paragallinarum. One loop full nutrient broth streaked on that media to get the colony of $A$. paragallinarum. Tiny dew drop colonies developed on blood agar media was considered positive for A. paragallinarum (Sameera et al., 2001; Blackall, 1989; Page et al., 1963).

\section{Gram's staining}

Gram's staining was done to determine the shape, arrangement and Gram reaction of the isolates as described by Merchant and Packer (1967).

\section{Biochemical test}

The carbohydrate fermentation test was carried out using suspected two isolates by inoculating a loop full of nutrient broth culture of the organisms into the tubes containing five basic sugars e.g., galactose, maltose, sucrose, and mannitol, glucose and incubated at $37^{\circ} \mathrm{C}$ for $24 \mathrm{hrs}$. Acid production was indicated by change of color from reddish to yellow in the medium (Jaswinder et al., 2004; Sameera et a1., 2001; Blackall, 1989; Hinz and Kunjara, 1977). 
Indole test

Two $\mathrm{ml}$ of peptone water was inoculated with five $\mathrm{ml}$ of bacterial culture and incubated at $37^{\circ} \mathrm{C}$ for $48 \mathrm{hrs}$. Kovac's reagent $0.5 \mathrm{ml}$ was added, mixed well and examined after one min. Development of red color indicate positive test (Jaswinder et al., 2004; Sameera et al., 2001).

\section{Methyl-Red and Voges-Proskauer (MR-VR) test}

These above two tests were carried out following the routine procedures as described by others (Jaswinder et al., 2004; Sameera et al., 2001).

\section{Catalase test}

The organism was grown on a slope of nutrient agar for $S$. aureus and blood agar for A. paragallinarum . One $\mathrm{ml}$ of $3 \% \mathrm{H}_{2} \mathrm{O}_{2}$ was run down the slope and examined immediately and after 5 mins for the evaluation of gas production. Positive test indicated by the production of bubbles (Cheesbrough, 1985; Carter, 1979).

\section{Maintenance of the stock culture}

Phosphate buffered saline solution: For preparation of phosphate buffered saline (PBS) solution, $8 \mathrm{gm}$ of sodium chloride, $2.89 \mathrm{gms}$ of disodium phosphate, $0.2 \mathrm{gm}$ of potassium chloride and $0.2 \mathrm{gms}$ of potassium hydrogen phosphate were suspended in $1000 \mathrm{ml}$ of distilled water. The solution was heated to dissolve completely then sterilized by autoclave at $121^{\circ} \mathrm{C}$ maintaining a pressure of 15 pounds per square inch for 15 mins and stored at refrigerator until use. The $\mathrm{pH}$ of the solution was measured by a pH meter and maintained at 7.0-7.2 (Cheesbrough, 1985).

Sterile buffered glycerin method: Sterile buffered glycerin (20\%) was prepared by mixing of 20 parts pure glycerin and 80 parts PBS. Then a loop full of thick bacterial culture of each isolate was mixed with $20 \%$ sterile buffered glycerin in small vial and was preserved at $-20^{\circ} \mathrm{C}$. This method was more appropriate for preserving bacteria with no deviation of their original characters for long time even for several years.

Gross pathology: Gross study was not carried out for 10 samples of S. aureus. Postmortem examination was carried out carefully on 30 dead chickens and 4 live chickens. Gross tissue changes such as mucus filled sinuses were observed and recorded carefully, and representative samples containing lesions were fixed in $10 \%$ neutral buffered formalin for histopathological examination.

Histopathology: Nasal passages of representative samples, from which isolation and identification of $A$. paragallinarum already done and clinically suspected IC were selected for routine histopathological study. Heads were decalcified before routine histopathological procedures (Luna, 1968). The formalin fixed tissues were trimmed, processed, sectioned and stained following standard procedure (Luna, 1968).

Photomicrography: Photomicrography was taken using camera (Olympus pM-c 35 Model) onto fitted with Olympus microscope (Olympus, Japan).

\section{Results and Discussion}

The results presented below demonstrate the isolation and identification of the etiological agent of IC from suspected cases of layer chickens. The samples collected from field cases were subjected to various cultural and biochemical investigation for the isolation of causal agent, and pathological study of the affected tissue.

\section{Isolation and identification of Staphylococcus aureus}

For the successful growth of Avibacterium paragallinarum the association of Staphylococcus aureus bacterial colony is needed for supplying of additional NAD. 


\section{Cultural examination of Staphylococcus aureus}

Swab samples from the nasal passage of 10 live chickens were inoculated separately in nutrient broth for $24 \mathrm{hrs}$ at $37^{\circ} \mathrm{C}$ and presence of bacteria was indicated by the turbidity of broth. All 10 samples showed turbidity in nutrient broth.

\section{Culture on mannitol salt agar}

Mannitol salt agar media was for the growth of Staphylococcus aureus. Ten swab samples were inoculated separately in mannitol salt agar for $24 \mathrm{hrs}$ at $37^{\circ} \mathrm{C}$ and the colony characteristics were round, smooth, shiny, opaque, golden yellow color resembling with the colony characteristics of Staphylococcus aureus (Fig. 1).

\section{Culture on nutrient agar}

Tentatively diagnosed five Staphylococcus aureus from mannitol salt agar media were streaked separately on nutrient agar for $24 \mathrm{hrs}$ at $37^{\circ} \mathrm{C}$. The colony characteristics of all five inoculated bacteria were round, smooth, shiny, opaque, golden yellow color which was indicating the colony characteristics of Staphylococcus aureus.

\section{Culture on blood agar}

Tentatively diagnosed five Staphylococcus aureus from mannitol salt agar media were streaked separately on blood agar and incubated for $24 \mathrm{hrs}$ at $37^{\circ} \mathrm{C}$. All of the samples showed yellowish, smooth colonies with no hemolysis were observed indicating the colony characteristics of Staphylococcus aureus (Fig. 2).

\section{Gram's stain}

Tentatively diagnosed five Staphylococcus aureus isolates from blood agar media were stained with Gram's stain. All five samples showed Gram-positive cocci and arranged in grape like clusters (Fig. 3).

\section{Catalase activity test}

Tentatively diagnosed five Staphylococcus aureus from blood agar media were subjected to catalase test. All five samples showed positive test (i. e. production of bubbles) indicating Staphylococcus aureus (Fig. 4).

\section{Culture of Avibacterium paragallinarum}

For the successful growth of $A$. paragallinarum additional NAD is needed. However Staphylococcus aureus grow in blood agar can produce additional NAD for the growth of $A$. paragallinarum. These blood agar media containing Stathylococcus aureus colonies were used for the culture of $A$. paragallinarum. Thirty swabs in nutrient broth from 30 dead birds died of other diseases revealed no growth of characteristic colonies of $A$. paragallinarum. Four clinical samples from nasal passages were inoculated separately in nutrient broth and incubated for $24 \mathrm{hrs}$ at $37^{\circ} \mathrm{C}$. All of the four samples showed turbidity in nutrient broth. (Fig. 7). These four samples from nutrient broth were cultured on blood agar media containing Staphylococcus aureus. Two out of four samples produced tiny dewdrops, mucoid, smooth iridescent colonies in blood agar media with no hemolysis in media resembling with the colony characteristics of $A$. paragallinarum (Fig. 8). These two isolates were preserved in sterile buffered glycerin for future use.

\section{Gram's stain}

Tentatively diagnosed two colonies of $A$. paragallinarum in blood agar media were stained with Gram's stain. Bacteria of all of the suspected two colonies showed Gram- negative, red color, rod shaped bacilli arranged as single or paired (Fig. 9). 
Biochemical tests of Avibacterium paragallinarum

Biochemical tests were performed from tentatively diagnosed two samples from blood agar media, a series of biochemical tests especially selective for $A$. paragallinarum were performed with the positive culture and Gram-negative rod shaped bacteria. The results were furnished below:

\section{Sugar fermentation test of Avibacterium paragallinarum}

All two isolates fermented four basic sugars (maltose, sucrose, and mannitol, glucose) and produced acid and did not ferment galactose. Acid production was indicated by the color change from reddish to yellow (Table 1, Fig. 10).

\section{Other biochemical tests of Avibacterium paragallinarum}

Two isolates were then subjected to different biochemical tests such as methyl-red test, VP test and indole test. All the isolates were methyl-red negative; VP test negative and indole test negative (Table 1, Figs. 11-13). Isolates revealed the following pattern of biochemical reactions regarded as $A$. paragallinarum.

Table 1. Results of Biochemical characteristics of $A$. paragallinarum

\begin{tabular}{|c|c|c|c|}
\hline Different Biochemical test & Sample size & Result & $\begin{array}{c}\text { Identification of } \\
\text { bacteria }\end{array}$ \\
\hline \multicolumn{4}{|c|}{ Fermentation reaction with five basic sugars } \\
\hline a. Glucose & \multirow{9}{*}{2} & + & A. paragallinarum \\
\hline b. Sucrose & & + & A. paragallinarum \\
\hline c. Galactose & & & A. paragallinarum \\
\hline d. Maltose & & + & A. paragallinarum \\
\hline e. Mannitol & & + & A. paragallinarum \\
\hline \multicolumn{3}{|l|}{ Other biochemical test } & \\
\hline Indole & & - & A. paragallinarum \\
\hline MR & & & A. paragallinarum \\
\hline MR-VP & & & A. paragallinarum \\
\hline
\end{tabular}

+ = Positive; - = Negative; MR = Methyl red; VP = Voges Proskauer

Catalase activity test for Avibacterium paragallinarum

Two isolates from blood agar media were subjected to catalase test. All the isolates showed negative test (i. e. production of no bubble) indicating A. paragallinarum (Fig. 14)

\section{Gross study}

Samples collected from 30 dead birds died due to other diseases showed no prominent gross lesions of rhinitis. However, four live birds showed clinical signs i. e. nasal discharge; conjunctivitis; swelling of the sinuses, face and wattles indicating cases of IC (Fig. 5). But only two out of four birds showed mucous in nasal passage and tracheal hemorrhage (Fig. 6).

\section{Histopathological study}

Thirty nasal passages from 30 dead birds died due to other diseases were not processed for histopathology as $A$. paragallinarum was not isolated from these cases. Two birds diagnosed of IC were processed for histopathological study. Microscopically, the section of the nose showed acanthosis, congestion, mucous glanduler cell hyperplasia, hyperplasia of nasal sinus and parakeratosis (Figs. 1516). 


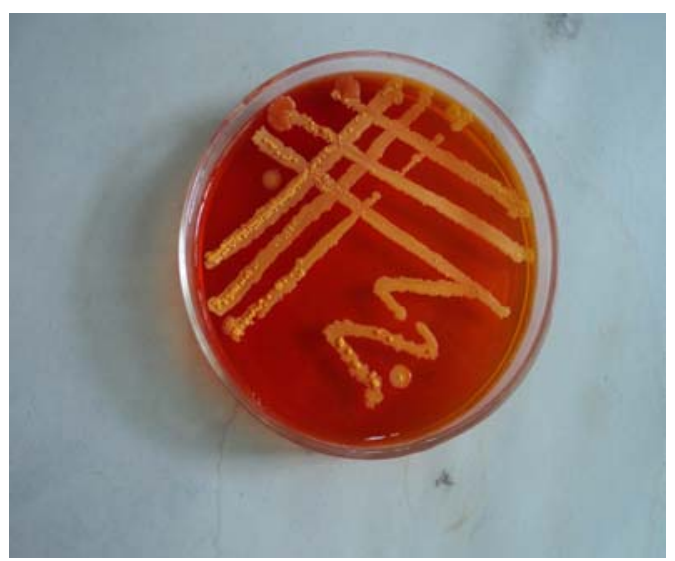

Fig. 1. Staphylococcus aureus produces golden yellow colored colony on mannitol salt agar media.

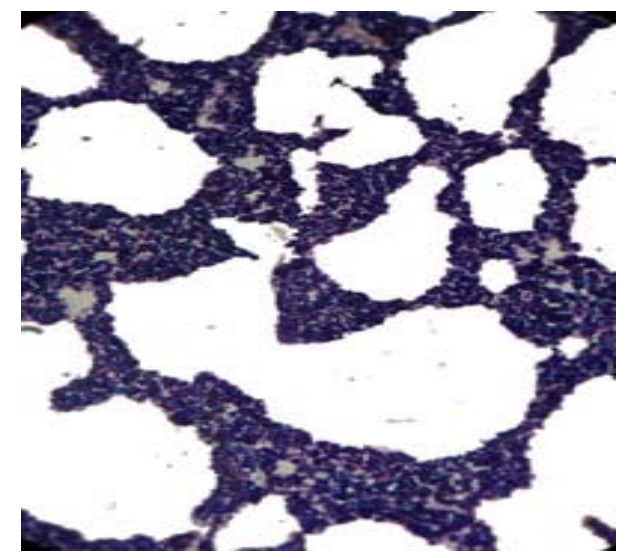

Fig. 3. Staphylococcus aureus showing gram positive, cocci and arranged in grape like clusters (Modified Gram's staining. x830)

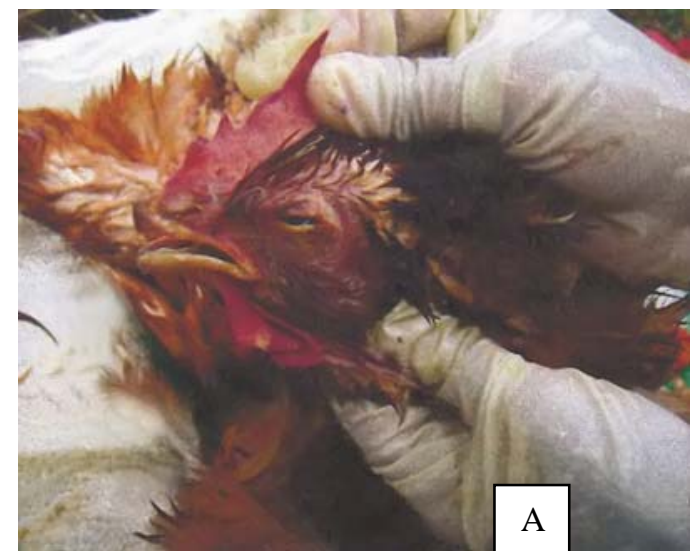

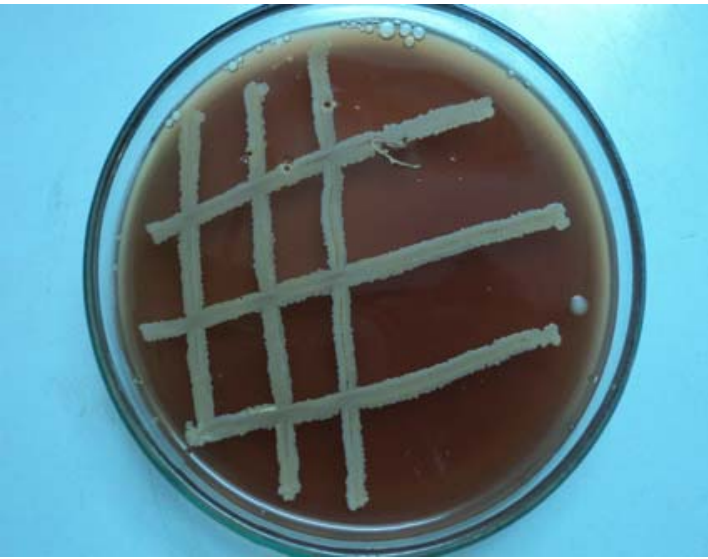

Fig. 2. Staphylococcus aureus produces yellowish colony on blood agar media.

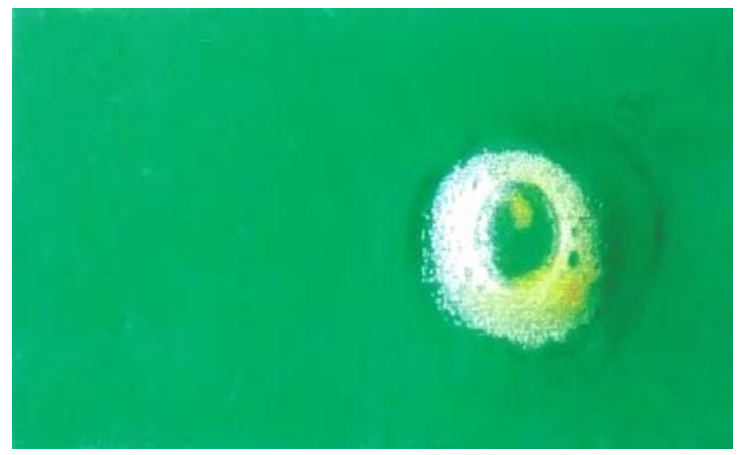

Fig. 4 .Production of bubbles which indicate catalase positive for Staphylococcus aureus

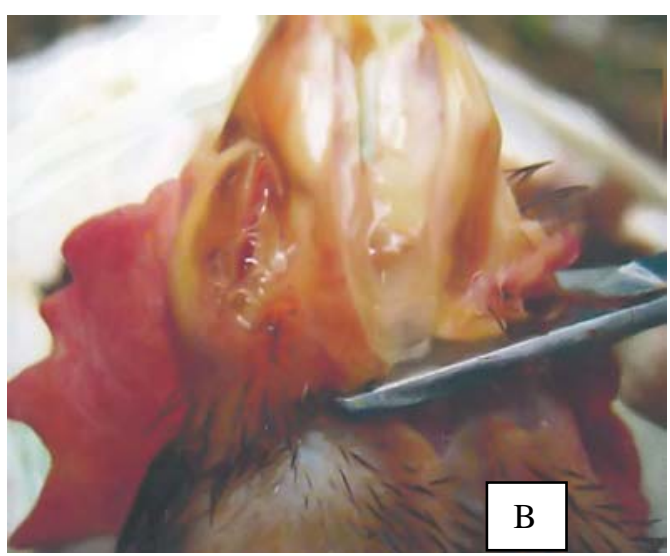

Fig. 5. Frothy oculo-nasal discharge (A and B) in IC infected chickens 

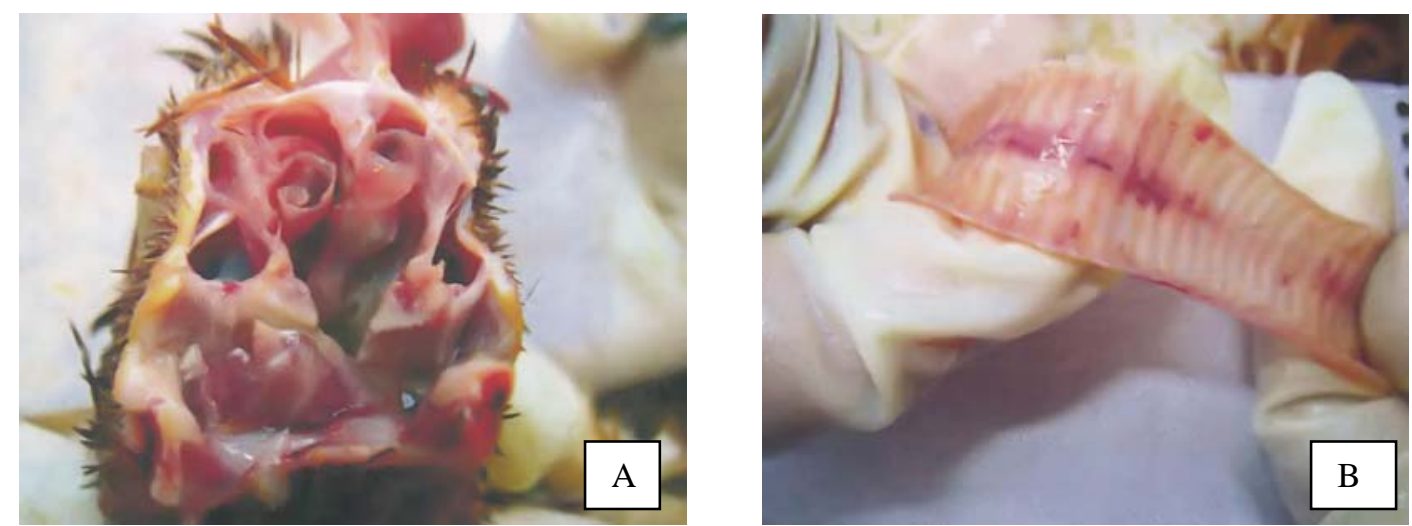

Fig. 6. Mucoid exudates in the nasal passage (A) and congested trachea (B) in IC infected chickens

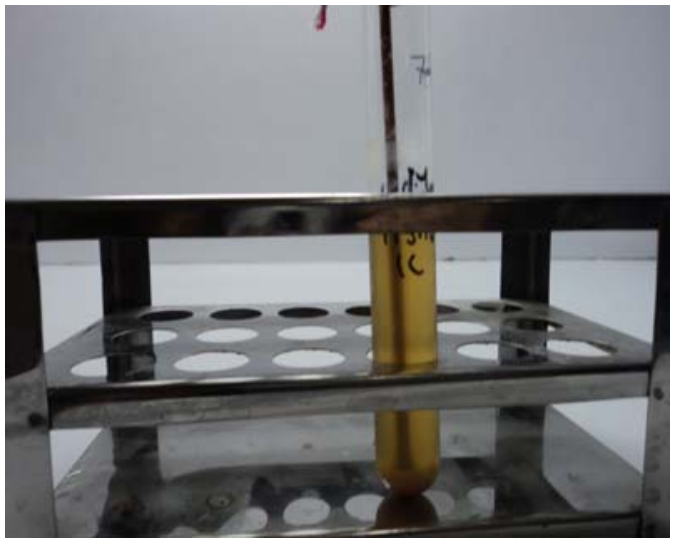

Fig. 7. A. paragallinarum produces turbidity in nutrient broth

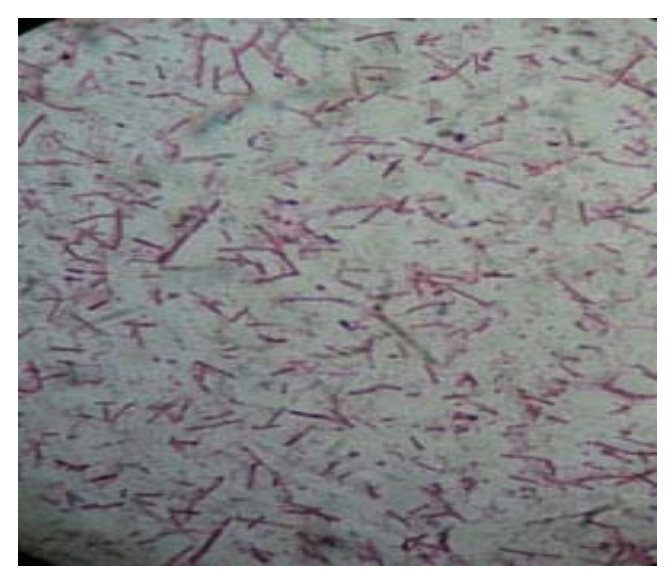

Fig. 9. A. paragallinarum showing gram negative rod shaped bacilli (Modified Gram's staining. x830)

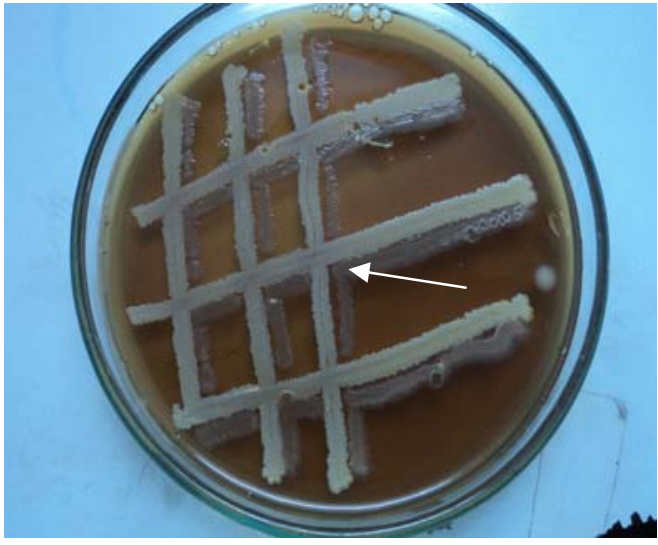

Fig. 8. A. paragallinarum produced smooth iridescent colonies with no hemolysis on blood agar media

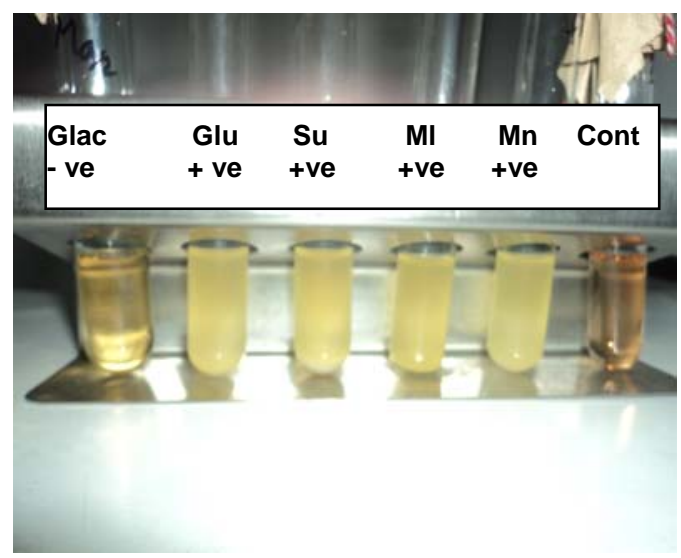

Fig. 10. Fermentation of glucose, sucrose, mannitol, maltose with production of only acid and no galactose by $A$. paragallinarum 


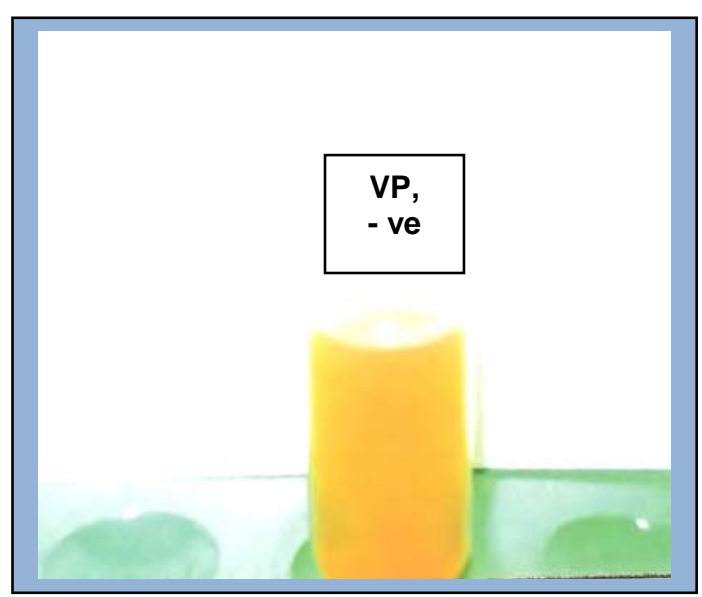

Fig. 11. A. paragallinarum produces yellow color in VP test, indicate negative reaction.

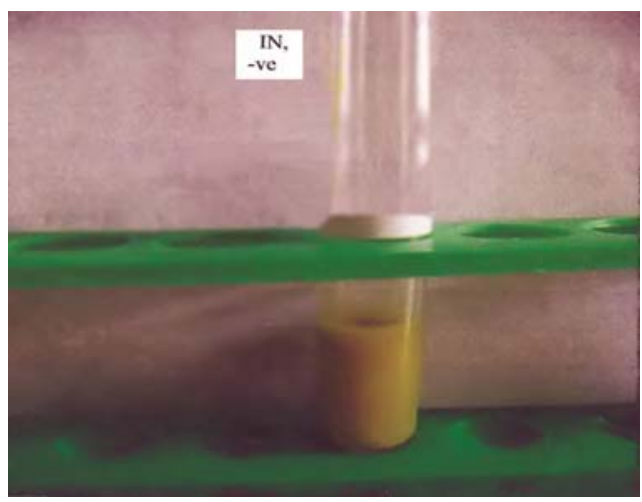

Fig. 13. Color change was not seen in indole test indicate negative reaction by infectious coryza

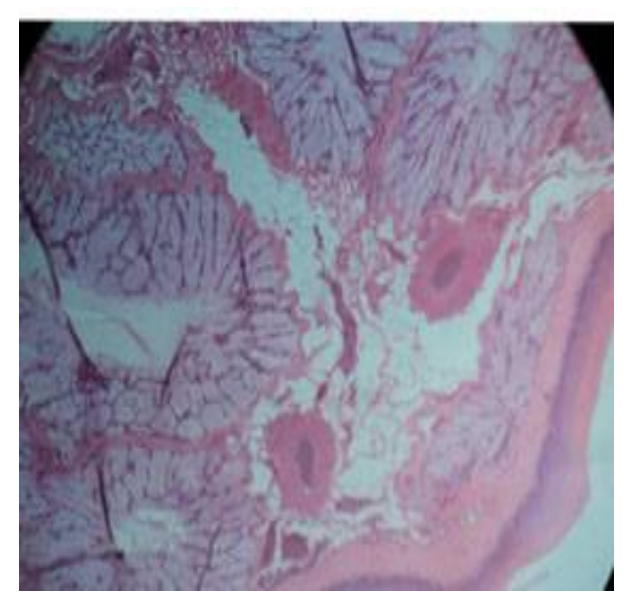

Fig. 15. Congestion and mucous glandular cell hyperplasia of $A$. paragallinarum affected nasal passage of chickens (H\&E stain, $X$ 333)

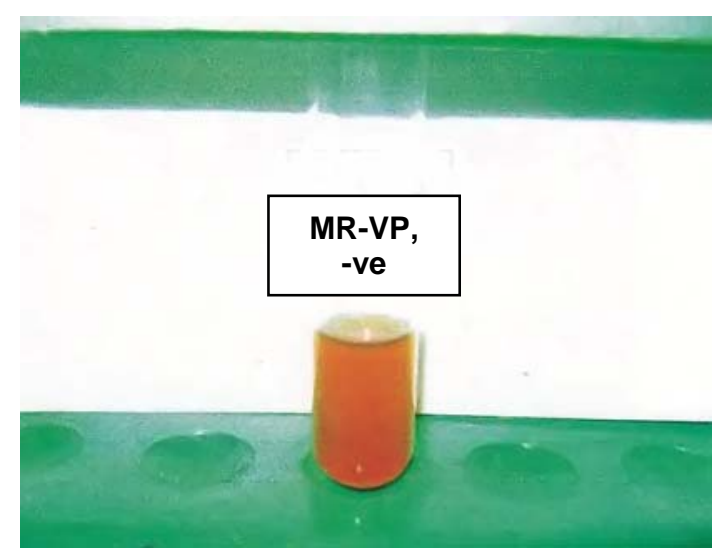

Fig. 12. A. paragallinarum produces yellow color in MR-VP test, indicate negative reaction.

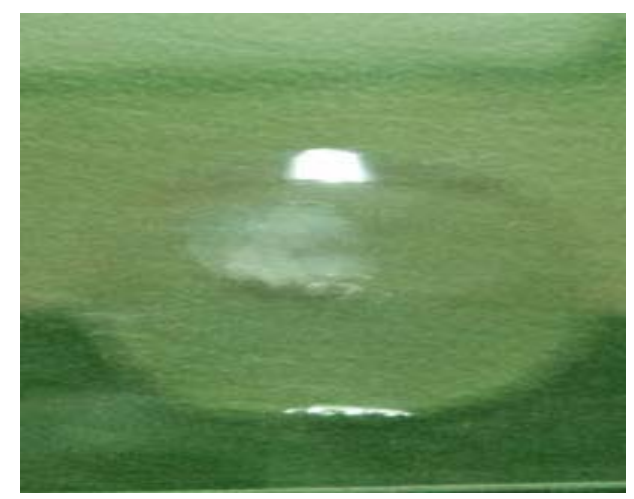

Fig. 14. Production of no bubbles indicate catalase nagative for $A$. paragallinarum

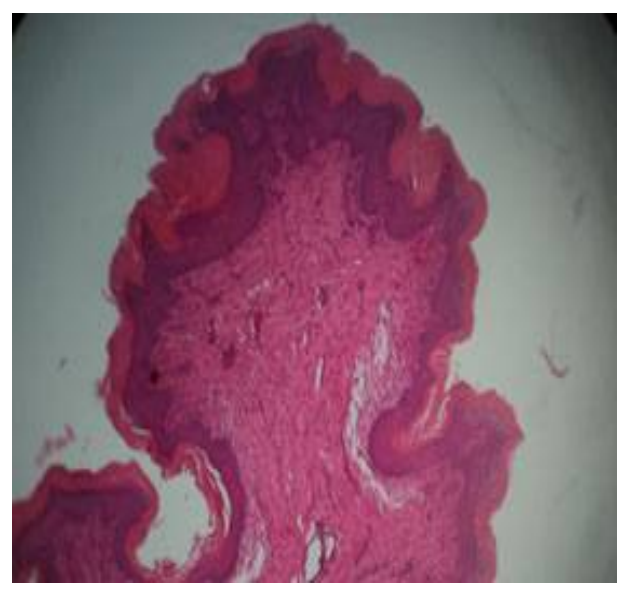

Fig.16. Acanthosis, parakeratosis and inflammatory cells of $A$. paragallinarum affected nasal passage of chickens (H\&E stain, $X$ 333) 
The present investigation was carried out for the isolation and identification of $A$. paragallinarum, the causal agent of IC, from layer chickens by cultural, morphological and biochemical examinations along with pathological investigation of the affected tissues.

For isolation and identification of $A$. paragallinarum additional NAD is required. However, the use of Staphylococcus aureus bacterial colony in the same media influences the growth of $A$. paragallinarum as it is reported that staphylococcus aureus bacterial colony supply additional NAD for A. paragallinarum. For isolation of $A$. paragallinarum an attempt was taken to isolate feeder bacteria Staphylococcus aureus. For this 10 nasal swab samples of live chickens were collected and all of them were positive for Staphylococcus aureus infection and were identified following cultural and morphological examination. These swabs were cultured in nutrient agar (NA), mannitol salt agar (MSA) and blood agar (BA) media. The colony characteristics of Staphylococcus aureus observed on nutrient agar (NA), mannitol salt agar (MSA) were smooth, shiny, opaque, golden yellow color and blood agar (BA) showed yellowish, smooth colonies with no hemolysis was similar to the findings of other authors (Brooks et al., 2002; Freeman, 1985; Merchant and Packer, 1967). In Gram's staining the morphology of the isolated Staphylococcus aureus appeared Gram-positive cocci and arranged in grape like clusters. These findings were in agreeable with several authors such as Brooks et al. (2002) and Carter (1979). The isolates also revealed positive reaction in catalase tests which was in agreement with Cheesbrough, 1985 and Carter, 1979.

For this study, a total of 34 nasal swab samples were collected ( 30 from dead birds and 4 from suspected clinical cases). Out of 34 nasal swab samples two were positive for $A$. paragallinarum infection and were identified following cultural, morphological biochemical examination and pathological study of the affected tissues. The colony characters on different media exhibited characteristic feature. The colony characteristics of $A$. paragallinarum observed on blood agar (BA) media containing Staphylococcus aureus tiny dewdrops, mucoid, smooth iridescent colonies with no hemolysis, similar to the findings of other authors (Sameera et al., 2001; Blackall, 1989; Page et al., 1963). The differences in colony morphology manifested by the isolates may be due to loosing or acquiring some properties by the transfer of host or choice of host tissue. However, our isolates did not show any variation in colony morphology.

In Gram's staining, the morphology of the isolated bacteria exhibited pink or small rod shaped Gram negative coccobacilli. These findings were in agreement with several authors (Jaswinder et al., 2004; Sameera et al., 2001; Yamamoto 1991; Sawata et al., 1980).

Our two isolates of $A$. paragallinarum was confirmed by sugar fermentation test. In this study, five basic sugars were used as stated by Blackall, (1989) and Hinz and Kunjara, (1977). All the isolates fermented glucose, sucrose maltose, mannitol but failed to ferment galactose within 24-48 hrs of incubation that supported the findings of others (Jaswinder et al., 2004; Sameera et a1., 2001; Blackall, 1989; Hinz and Kunjara, 1977).

To reconfirm the isolates as $A$. paragallinarum some other biochemical test was carried out. The isolates also revealed negative reaction in MR test, Indole test, V-P test and catalase tests which was in agreement with other authors (Jaswinder et al., 2004; Sameera et al., 2001).

Clinically suspected IC was characterized by nasal discharge, conjunctivitis with swelling of the sinuses, face and wattles, decreased feed and water consumption, and reduced egg production and in necropsy examination the gross lesions noticed were mucous in nasal passage and tracheal hemorrhage. Similar observations were made by Welchman, (2010), Miao et al., (2001), Haunshi et al., (2006), Ibrahim et al., (2004), Kurkure et al., (2001). Histopathological study from two cases from where A. paragallinarum was isolated. Representative sections from nose showed acanthosis, congestion of blood vessels, hyperplasia of mucous glandular cells, hyperplasia of nasal sinus and parakeratosis. These observations were in agreement with Miao et al., (2001), Haunshi et al., (2006), Jaswinder et al., (2005), Ibrahim et al., (2004), Kurkure et al., (2001) and Sameera et al., (2001). To our knowledge, this is the first time that the isolation and identification of $A$. paragallinarum was carried out in Bangladesh. From the above, since IC is a disease of great economic importance in commercial poultry industry and creates havoc, thus more detailed examinations including effects on vital organs need further examination. 


\section{Acknowledgement}

The authors are grateful to BAURES, Bangladesh Agricultural University, Mymensingh, Bangladesh for financial support.

\section{References}

Alder, H.E. and Page, L.A. 1962. Hemophilic infection in chickens. II. The pathology of the respiratory tract. Avian Dis., 6: 1-6.

Beach, J. R. and Schalm, O. W. 1936. Studies of the clinical manifestations and transmissibility of IC in chickens. Poult. Sci. 15:466470.

Blackall, P.J. 1989. The Avian Haemophili. Clin. Microbiol. Rev., 2: 270-277.

Brooks, G.F., Butel, J.S. and Morse, S.A. 2002. Jawetz, Melnick and Adelberg's Medical Microbiology. $22^{\text {nd }}$ end. MacGraw Hill, New Delhi, India. 197-202.

Calnek, B.W.H., John Barnes, C.W., Breed, W.M., Reid and Yodev, H.W. 1991. Diseases of Poultry, 9th Ed. Wolfe Publishing Ltd., USA. pp. 186-192

Carter, G.R. 1979. Diagnostic Procedures in Veterinary Bacteriology and Mycoplasma. $3^{\text {rd }}$ edn. Charles C. Thomas Publisher U. S. A. pp. 398-417.

Cheesbrough, M. 1985. Medical laboratory manual for tropical countries. $1^{\text {st }}$ edn. Vol. 2 Microbiology, English Language Book Society, London, 35: pp. 40-57.

De Blieck, L. 1932. A haemoglobinophilic bacterium as the cause of contagious catarrh of the fowl. Vet. J., 88: 9-13.

Eaves, L.E., Rogers, D.G. and Blackall, P.J. 1989. Comparison of Haemophilus paragallinarum and proposal of a new hemagglutinin serovar. J. Clin. Microbiol., 27: 1510-1513.

Freeman, B.A. 1985. Burrow's Text Book of Microbiology. $22^{\text {nd }}$ end. W. B. Saunders Company, London, UK. pp.372-472.

Giurov, B. 1984. Clinical cases of IC and the properties of isolated Haemophilus strains. Vet. Med. Nauki., 2 I (7 -8):22-30.

Haunshi, S., Dutta, B. and Saxena, S.C. 2006. An outbreak of IC in Vanaraja poultry of Meghalaya. Ind. J. Vet. Pathol., 30(1):55.

Hinz, K.H. and Kunjara, C. 1977. Haemophilus avium: a new species from chickens. Int. J. Systematic Bacteriol., 27 :324-329.

Ibrahim, R.S., Mousa, S., Aly, M. and Abdel Naser, W.E. 2004. Complicated IC in broiler and layer chickens in Upper Egypt. Assiut Vet. Med. J., 50 (103): 94-108.

Jaswinder Kaur, Sharma, N.S., Kuldip Gupta and Amarjit Singh. 2004. Epidemiological studies on IC in chickens in northern India. Ind. J. Animal. Sci., 74(5): 462-465.

Kurkure, N.V., Bhandarkar, A.G., Ganokar, A.G. and Kalorey, D.R. 2001. A report on occurrence of infectious coryza in a commercial layer farm of vidharbha. Ind. J. compt. Microbiol.Immunol. Infect. Dis., 22(2): 176.

Luna, L.G. 1968. Manual of histologic staining methods of the Armed Forces Institute of Pathology. 3rd ed. McGraw-Hill, New York.

Merchant, I.A. and Packer, R.A. 1967. Veterinary Bacteriology and Virology $7^{\text {th }}$ edn. The lowa University Press, Ames lowa, U. S. A. pp. 286-306.

Miao-DeYuan, Zhang-PeiJun, Gong-YuMei and Miao-DeRong. 2001. Studies on dynamics of antibodies in sera from chickens vaccinated with bivalent inactivated oil adjuvant vaccinc to infectious coryza. Acta-Agricurturae-Boreali-sinica., 16 (3):135139.

Page, L.A. 1962. Haemophilus infection in chickens. 1. Characteristics of 12 Haemophilus isolates recovered from diseased chickens. Am. J. Vet Res., 23:85-95.

Page, L.A., Rosenwald A.S and Price, F.C. 1963. Haemophilus infections in chickens: V. Results of laboratory and field trials of formalinized bacterins for the prevention of disease caused by Haemophilus gallinarum. Avian Dis., 7:239-256.

Reid, G.G. and Blackall, P.J. 1984. Pathogenicity of Australian isolates of Haemophilus paragallinarum and Haemophilus avium in chickens. Vet. Microbiol., 9:77-82.

Sameera Akhtar; Asif Rasool Bhatti and Khushi Muhammad. 2001. Clinico-Therapeutic Observations on an Outbreak of Infectious Coryza. Int. J. Agri. Biol., 03(4):531-532.

Sawata, A., Kume, K. and Nakase, Y. 1980. Biological and serological relationships between Page's and Sawata's serotyping of Haemophilus Paragallinarum. Am. J. Vet. Res., 41:1901-1904.

Talha, A.F.S.M., Hossain, M.M., Chowdhury, E.H., Bari, A.S.M., Islam, M.R. and Das, P.M. 2001. Poultry diseases occurring in Mymensingh district of Bangladesh. Bangladesh Vet., I8 (1): 20-23.

Welchman. 2010. Infectious coryza in chickens in Great Britain. Vet. Rec., 167: 912-913

Yamamoto, R. 1991. Infectious coryza. In: Diseases of Poultry, $9^{\text {th }}$ ed. M. S. Hofstad, H. J. Bames, B. W. Calnek, W. M. Reid, and H. E. Yonder, Jr., eds,. Lowa State University Press, Ames, lowa. pp. 186-195. 